\title{
EDUCAÇÃO ESCOLAR E HIGIENIZAÇÃO DA INFÂNCIA
}

\author{
Heloísa Helena Pimenta Rocha* \\ Educação vale mais que as leis, é o moto desta época. \\ A persuasão substituindo a imposição. \\ (Paula Souza)
}

\begin{abstract}
RESUMO: Este artigo analisa o modelo de educação sanitária formulado no interior da ampla campanha de regeneração física, intelectual e moral a que se lançou o Instituto de Hygiene de São Paulo, instituição criada em 1918, em cooperação com a Junta Internacional de Saúde da Fundação Rockefeller. Busca compreender as representações sobre a infância e as práticas por meio das quais os médicos-higienistas paulistas procuraram intervir sobre os corpos e as mentes das crianças. Para tanto, toma como fontes documentos produzidos no âmbito do Departamento de Higiene Escolar do Instituto, conferindo especial atenção àqueles que permitem apreender o papel atribuído à escola primária na obra de disciplinamento e conformação da infância aos imperativos da racionalidade higiênica.
\end{abstract}

Palavras-chave: Escolarização. Higienização. Educação sanitária. Infância.

\section{SCHOOL EDUCATION AND THE HYGIENE OF CHILDREN}

ABSTRACT: This paper analyzes the model of sanitary education formulated during the wide campaign of physical, intellectual and moral regeneration launched by the São Paulo Institute of Hygiene, created in 1918, in cooperation with the International Health Board of the Rockefeller Foundation. It also tries to understand the representations of childhood and the practices through which the

Doutora em Educação pela Universidade de São Paulo (USP), professora na Faculdade de Educação da Universidade Estadual de Campinas (UniCamp) e membro do comitê gestor do Centro de Memória da Educação/unicamp. E-mail: heloisah@unicamp.br 
doctor-hygienists from São Paulo tried to interfere on the bodies and minds of children. Therefore, its sources are documents produced within the department of School Hygiene of that Institute, especially those that allow apprehending the role attributed to primary school in the education process and in the conformation of childhood to the imperatives of the hygienic rationality.

Key words: Schooling. Hygienization. Sanitaryeducation. Childhood

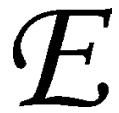

liminar atitudes viciosas e inculcar hábitos salutares, desde a mais tenra idade. Criar um sistema fundamental de hábitos higiênicos, capaz de dominar, inconscientemente, toda a existência das crianças. Modelar, enfim, a natureza infantil pela aquisição de hábitos que resguardassem a infância da debilidade e das moléstias. Eis as tarefas de que se deveria incumbir a escola primária, no contexto da reforma que redefiniu o eixo da política sanitária paulista, na década de 1920. Tarefas que, aliás, pareciam ser reconhecidas como do âmbito específico da instituição escolar. Não é demais lembrar, neste sentido, que, concebida como cenário privilegiado de um conjunto de práticas voltadas para o disciplinamento da infância, a escola vem sendo, recorrentemente, chamada a oferecer sua poderosa colaboração para o sucesso de campanhas que visam ao combate de endemias e epidemias, como também para a difusão de meios de prevenção e preservação da saúde. Campanhas essas pautadas em representações sobre a saúde, a doença, a infância e, ao mesmo tempo, em uma inabalável crença no poder modelador da educação e da escola.

Intentando dar conta das representações sobre a infância produzidas pelos médicos-higienistas paulistas e das práticas por meio das quais procuraram intervir sobre os corpos e as mentes das crianças, este artigo ${ }^{1}$ analisa o modelo de educação sanitária formulado na esteira da campanha de regeneração física, intelectual e moral a que se lançou o Instituto de Hygiene de São Paulo, instituição criada em conformidade com os moldes norte-americanos de abordagem dos problemas de saúde pública, caracterizados pela centralidade conferida à formação da consciência sanitária do indivíduo na prevenção das doenças. Para tanto, toma como fontes documentos produzidos no âmbito do Departamento de Higiene Escolar do Instituto, examinando, mais especificamente, a tese de doutoramento apresentada pelo Dr. Antonio de Almeida Junior à Faculdade de Medicina e Cirurgia, em 1922, intitulada $O$ saneamento pela educação, na qual podem ser identificadas as linhas-mestras que orientaram as 
iniciativas encetadas por essa instituição no sentido de legitimar a educação sanitária como instrumento de higienização da população.

\section{"A era da higiene"}

A criação do Instituto de Hygiene, atual Faculdade de Saúde Pública da Universidade de São Paulo, resultou de um acordo entre o governo do Estado de São Paulo e a Junta Internacional de Saúde da Fundação Rockefeller, em 1918, tendo em vista o provimento da cadeira de Higiene da Faculdade de Medicina e Cirurgia de São Paulo. Comprometido com o ensino científico da higiene e a preparação de técnicos para o provimento dos cargos de saúde pública, o Instituto foi oficializado em 1924 - pela Lei $n^{\circ} 2.018$, que definiu as suas atribuições e competências -, passando por sucessivas alterações estruturais, que foram consolidando a sua autonomia.

No período de $1922-1927,{ }^{2}$ essa instituição passou a assumir um lugar de destaque na formulação da política sanitária estadual, participando, de forma decisiva, da produção de um discurso científico sobre as questões urbanas e da elaboração de estratégias de intervenção que, tendo como objetivo central a formação da consciência sanitária, colocavam a educação sanitária em primeiro plano, deslocando a ênfase dos já conhecidos métodos de policiamento sanitário para modernos métodos de persuasão. ${ }^{3}$ Deslocamento esse que não correspondeu ao abandono das práticas policialescas, as quais passariam a se revestir de uma nova roupagem.

Nesse momento, em que o discurso higienista passa a se articular em torno do binômio educação e saúde, o Instituto de Hygiene constituiu-se também num espaço importante na articulação de estratégias voltadas para a veiculação da mensagem da higiene no universo escolar, quer pela sua atuação na formação profissional dos professores primários, quer pela formação de agentes de saúde pública, quer, ainda, pela produção de impressos destinados, entre outros públicos, às crianças das escolas primárias e a seus mestres. É na esteira dessas iniciativas que se pode compreender a organização do Departamento de Higiene Escolar, em 1922, sob a direção do Dr. Antonio de Almeida Junior, lente de Biologia e Higiene da Escola Normal do Braz e assistente pensionado do Instituto. A análise da sua tese de doutoramento, intitulada $O$ saneamento pela educação, elaborada no Instituto de Hygiene e apresentada à Faculdade de Medicina, em 1922, oferece importantes 
elementos para a compreensão das representações sobre a infância que perpassaram as propostas de educação sanitária elaboradas por essa instituição.

Postulando a necessidade da aproximação entre educação e higiene, Dr. Almeida Junior procura construir, em seu trabalho, a idéia do amplo reconhecimento da importância da higiene no enfrentamento dos problemas sanitários:

Estamos, agora, na éra da hygiene. Cimenta-se, no espirito dos que observam e investigam a convicção de que o futuro humano depende, preponderantemente, da obediencia ás normas sanitarias, por parte das sucessivas geraçôes; e que a incuria e o menoscabo, no tocante á hygiene, tem sido e está sendo de consequencias funestas. (Almeida Junior, 1922, p. 29)

A obediência do indivíduo aos ditames da higiene configura-se como a fórmula que se apresenta ao espírito daqueles que observam e investigam os problemas gerados pelo rápido crescimento das cidades e pelas condutas desregradas da população. Estancar a torrente mórbida, a grande ameaça que pairava sobre a sociedade, era o desafio diante do qual se colocavam os médicos-higienistas. Desafio esse cujo enfrentamento exigia um programa de disciplinamento da população, o qual deveria fundamentar-se na articulação entre higiene e moral:

Comprehende-se que não basta sanear o ambiente. O homem alheio á hygiene é o maior viveiro de germens pathogenicos, e o mais activo popularisador de molestias. Só elle mesmo, pela sua propria vontade, aquecida pela educação moral e orientada pela instrucção hygienica, poderá estancar a fonte morbigena. (Idem, ibid., p. 11)

Concebendo os problemas sanitários como problemas de ordem educativa, cuja solução passava pela inculcação de modos de viver calcados nos parâmetros da ciência, Dr. Almeida Junior defende a necessidade de buscar o concurso da escola primária na importante causa do saneamento do Brasil. Fator essencial na formação moral e intelectual do povo, a escola primária é vista como a instituição a cuja força e poder deveriam recorrer os higienistas. Assim,

mais uma vez, portanto, se appella para a escola. Reconhece-se que á ameaça de um grande mal, tão tristemente prenunciado, temos que oppor a barreira da grande força da escola primaria. Agindo em massa, lenta e continuamente, graças á sua universalidade e obrigatoriedade, é ella susceptivel de alcançar a todos, no tempo e no espaço. (Idem, p. 33) 
Diante dessas afirmações, caberia indagar: em que residiria o enorme poder dessa instituição? Como se justificariam os intentos de alçá-la ao lugar de eixo da educação sanitária? Essas questões põem em relevo o elemento central sobre o qual se alicerça a tese do Dr. Almeida Junior, aquele sobre o qual repousam desde as justificativas para o apelo à escola por parte dos médicos-higienistas até os fundamentos para a escolha dos métodos, procedimentos e recursos a adotar na educação sanitária - a teoria do hábito, fundada no suposto da plasticidade infantil. Assim, o precioso concurso da escola primária não poderia ser dispensado na medida em que

sua acção se exerce sobre o cerebro infantil ainda plastico, virgem de defeitos, e póde, por isso, afeiçoar-lhe a estructura mental, oriental-o, e incutir-lhe um systema duradouro de habitos. Ella só é capaz. Armada a autoridade que a sua propria essencia lhe dá, guiada pelo espirito do mestre, em que se alliam o saber e o methodo, a intelligencia e o coração, nenhum outro apparelho existe, nem existirá, cuja acção se lhe possa comparar. Sómente ella é efficaz. Porque, em seu rumo, não encara este ou aquelle problema da hygiene, mas todos; não faz prophylaxia desta ou daquela molestia, mas de todas; não se endereça a esta ou aquella classe, mas á universalidade social. (Idem, p. 33)

Leitor de Gustave Le Bon, ${ }^{4}$ Maudsley, ${ }^{5}$ William James ${ }^{6}$ e Herbert Spencer, ${ }^{7}$ Dr. Almeida Junior derivaria a sua proposta de educação sanitária da concepção de educação como arte de formar hábitos. Concepção que justificaria tanto a apropriação da infância como objeto privilegiado de intervenção quanto o papel central atribuído à escola primária na educação sanitária. ${ }^{8}$

Assim, diante da questão: "A quem endereçar a educação? Ao adulto ou á creança?", não parecia pairar nenhuma dúvida de que "só a creança é realmente educavel” (idem, p. 19) e de que, neste sentido, todo esforço educativo deveria privilegiar a infância, reservando-se, para a idade adulta, a instrução, vista como possibilidade de reforçar alguns hábitos. Reportando-se à analogia spenceriana entre o sistema nervoso e o curso da água sobre uma superfície lisa, indaga: "Que ondas haveria, capazes de esculpir um sulco profundo e duradouro no systema nervoso do adulto, cuja plasticidade se exgotou atravez da infancia e da adolescencia, e cuja permeabilidade se obstruio, por tantas e tão variadas correntes anteriores?" (idem, p. 26). E sentencia:

A época de maior capacidade para a acquisição de habitos é, pois, a infancia. Á medida que o individuo se approxima da idade adulta ou 
nella caminha, maior resistencia offerece ás novidades. A excitação nervosa póde impressionar os centros cerebraes: mas a impressão, por funda que seja, é transitoria. (...). Dahi a necessidade de fazer-se a educação tão cedo quanto possivel. Toda a espera é nociva. Alem da plasticidade, que se vai esmorecendo, uma infinidade de impressões indesejaveis vêm continuamente occupar logar, no cerebro, e obstruil-o. (Idem, p. 26-27)

O contraste entre a infância e a idade adulta, por meio do qual a idade adulta é representada pelo progressivo enrijecimento, em contraposição à plasticidade infantil, oferece importantes elementos para a compreensão da noção de hábito e do seu papel na obra de modelagem da infância, que deveria configurar-se no objetivo central da educação sanitária:

É possivel, na idade adulta, a acquisição e o desenvolvimento de habitos isolados. (...) Mas o que é difficilimo, para não dizer irrealizavel, nessa epoca, é a creação de um systema fundamental de habitos, dominando a existencia inteira, a toda a hora, em todas as opportunidades, sob todos os pretextos, inconscientemente, sem o menor esforço, como devem e precisam ser os habitos hygienicos. Estes, para sua efficacia, terão de formar um complexo cerrado, sem ponto vulneravel, e hão de calar tão fundamente no espirito e na actividade, que passem a constituir, não a "segunda natureza", como os demais habitos, mas a natureza mesma do individuo. (Idem, p. 27)

Como um anjo da guarda invisivel e silencioso, o sistema de hábitos que se pretendia instaurar não deveria se restringir a um ou outro hábito isolado, tampouco deveria limitar-se a configurar uma segunda natureza. Encerrando a criança em um complexo cerrado, sem ponto vulnerável, capaz de dominar-lhe a existência inteira e de agir inconscientemente, tal sistema deveria se constituir na própria natureza da criança. A garantia da sua eficácia estribava-se na maleabilidade e plasticidade infantis:

Modelamento assim, tão accentuado e tão vultuoso, só se obtem na plasticidade ceracea do systema nervoso infantil. Porque, pois, esperar a idade adulta? Porque não barrar o individuo, em seu transito pela meninice, e não organizar-lhe, nessa phase da vida, a estructura mental, sob o ponto de vista hygienico, municiando-lhe a actividade de habitos que, como um circulo de ferro, o protejam contra a debilidade e a molestia? Não cremos que aos responsaveis pelo bem collectivo sejam extranhos estes conceitos. O que, porem, não se negará, é que elles estão longe ainda da applicação que merecem. (Idem, p. 27) 
Diante dessa extraordinária possibilidade de modelamento oferecida pela maleabilidade da infância, Dr. Almeida Junior indagaria: Como admitir que a escola primária continuasse a responder pelo silêncio aos apelos dos higienistas? Como admitir que dotada de tamanho poder, ela continuasse arraigada a velhas concepçôes e limitada, na sua atuação, em função de inadequados programas, obsoletos métodos e processos de ensino e da insuficiente formação de professores? Como admitir, enfim, que a sua contribuição para a obra de regeneração da população fosse praticamente nula?

Calcada em representações da infância que a identificam à matéria plástica, permeável, virgem de defeitos e de impressões indesejáveis, a proposta do Dr. Almeida Junior apela, pois, para a materialização da era da higiene na organização da escola primária paulista:

Tivemos, na escola primaria, a éra da leitura analytica, a da calligraphia vertical, a do desenho do natural, a da musica analytica, a do escotismo, todas as grandes linhas, emfim, que caracterisam o ensino paulista e the dão, no referente á technica, incontestavel superioridade. Que chegue agora a vez da hygiene. (Idem, p. 42)

Tal proposta exigia, evidentemente, uma revolução copernicana nos métodos e processos de ensino e na formação dos professores. Revolução que, deslocando os métodos de ensino da lição teórica, das regras e conselhos, possibilitasse a fixação de um conjunto de hábitos voltados para a preservação da saúde individual e coletiva. Reclamando para o ensino da higiene as vantagens do que denominava de learning by doing, afirmaria o autor:

O "conselho" é a base do ensino. No entretanto, nenhum assumpto merece mais do que a hygiene os favores da methodologia. Nenhum precisa tanto do "ensino activo", pelo qual a creança investiga, descobre, critica e faz. A educação hygienica, bem entendida, é um conjuncto de habitos, convergindo todos para a defeza da saude individual ou collectiva. E não se adquirem habitos pela audição, pela leitura ou pela copia de preceitos. Os habitos resultam da permeabilidade das vias nervosas. É a acção que os géra. É a actividade continuada que os aperfeiçoa e os fixa. (Idem, p. 45)

As novas feições que se pretendia dar à educação sanitária, mais coerentes com os objetivos de inculcação de hábitos, tinham por base a afirmação do primado da psicologia na discussão das questôes pedagógicas. Distinguindo a pedagogia do bom senso e procurando conferir-lhe caráter de cientificidade, o autor invoca a psicologia como 
ciência capaz de ensinar sobre a natureza da criança e, por essa via, de responder às questóes que dizem respeito às formas de ensinar, evitando os maus hábitos e inculcando os bons.

A pedagogia não é o "bom senso" espesso e vulgar, applicado ao ensino. O bom senso suppõe apenas a posse dos conhecimentos que constituem o cabedal indifferente de toda a gente; e com esse cabedal a pedagogia não se contenta. Ella exige a sciencia da natureza infantil, do modo pelo qual desabrocha e se desenvolve o espirito da creança, e, assim armada, investiga os meios educativos mais sagazes e opportunos. O educador terá, pois, de conhecer as dominantes da psychologia do alumno, pelo menos desde que este inicia, até que interrompe o seu contacto com a escola. (Idem, p. 46)

É com base no conhecimento dessa ciência da natureza infantil que Dr. Almeida Junior se propóe a traçar um programa para o ensino da higiene na escola primária, cujos sagazes e oportunos meios educativos favorecessem a urgente tarefa de formação da consciência sanitária. Num crescendo que vai das atitudes e dos comportamentos à cognição, passando pelos sentimentos, o trabalho educativo deveria ser arquitetado com base em princípios que encontrariam nas práticas escolares os seus correspondentes. Tais princípios, enunciados numa sequêencia que corresponde ao caminho que a criança deveria percorrer na aquisição dos hábitos higiênicos, são: a imitação, a obediência, o amor-próprio e, por último, o raciocínio.

Reservando para as classes mais adiantadas os estudos pormenorizados, que permitissem entender os porquês dos preceitos sanitários, esse modelo de ensino se funda na aproximação entre higiene e moral:

Neste particular, a educação hygienica se approxima da educação moral: tem de iniciar-se dogmatica. O alumno se fiará na sciencia do mestre. Explique este só o que puder ser comprehendido. Mas não adie os habitos e conselhos cujos fundamentos estejam acima da intelligencia infantil. Quando for possivel, virá a razão de ser. E si não vier, ficarão, em todo o caso, os habitos. E os habitos são quasi tudo. (Idem, p. 48)

Dogmatismo que, no intento de imprimir hábitos, lança mão da tendência da criança à imitação - "lei natural, tanto mais imperiosa quanto menos maduro o espirito" -, da obediência, que decorre da autoridade do professor, e do amor-próprio associado à emulação. Arma de dois gumes, a imitação, por ser avessa ao discernimento entre o vício e a virtude, exigiria do professor a necessária precaução. Prêmios, 
sanções sociais e morais, reforçando a autoridade do professor, contribuiriam decisivamente no sentido de fazer com que a "vontade inerte ou mal orientada do alumno" recebesse "a influência benefica da autoridade do professor” (idem, p. 47). O amor-próprio, habituando a criança a ver e rejeitar os pecados contra a higiene e contribuindo, desse modo, para a introjeção da vigilância, figura como outro princípio de importância crucial nessa obra de modelamento que, associado à emulação, ganharia um extraordinário poder:

O amor proprio presta á hygiene a mesma cooperação que aos demais ramos educativos. Quando a creança apprender, pelo trabalho constante da escola, a distinguir as particularidades da falta de asseio, quando se habituar a "vêr" as unhas sujas, o rosto mal lavado, os cabellos em desalinho, não lhe escaparão mais á argucia os seus proprios pecadilhos, e o amor proprio, prudentemente cultivado, fará o resto. Uma discreta emulação entre os alumnos manterá em cada um o desejo de apresentar-se, dia a dia, mais de accordo com os preceitos sanitarios; e o bem estar physico, creado pela limpeza e pela ordem do vestuario, correrá parelhas com o bem estar moral. (Idem, p. 48)

Rematando essa obra, o raciocínio. Parte do grupo das ciências da natureza, a higiene deveria afastar-se da frieza dos compêndios e das enfadonhas exposiçóes magistrais, primando por um ensino objetivo e pelo contato direto com os fatos. Nesse percurso, que vai da imitação ao raciocínio, "o que o habito fixa, a intelligencia comprehende e explica, armando melhor o individuo para adaptar-se ás condiçóes novas e imprevistas, que constituem uma grande parcella da vida" (idem, p. 49).

Visando a atingir a aquisição de hábitos e desenvolver a capacidade de compreensão e adaptação, a educação sanitária deveria ancorar-se em vários elementos concretos, dentre os quais se destaca um conjunto de práticas que deveriam instituir-se no cotidiano da escola, conformando os corpos e as mentes dos alunos.

\section{A exposição das práticas exemplares}

Materializando-se em lugar da saúde, a escola, aberta à luz do sol e ao ar, limpa, espaçosa, ordenada e clara, exerceria por si só uma poderosa sugestão higiênica sobre as crianças. Contrastando com a sujeira dos seus sapatos e das suas mãos, o assoalho limpíssimo e os móveis polidos e lustrosos ensinariam às crianças a necessidade de limpar a sola dos sapatos e lavar as mãos. Agindo sobre a tendência 
à imitação, a escola, impecavelmente limpa e iluminada, transbordaria a sua ação educativa para o ambiente doméstico, "e assim, a installação escolar, pela sua simples força de presença, irá repercutir nas condiçôes sanitarias do domicilio" (idem, p. 49). Quando a força da presença por si só não bastasse, quando a sugestão higiênica fosse insuficiente, usasse o professor da sua autoridade, matizando o contraste entre a escola e o lar, entre a virtude e o vício.

Exemplo de virtude, a figura do professor teria também sobre a criança, impressionável e plástica, um enorme poder de sugestão, transmitindo-lhe "hábitos de asseio, modos de arranjar-se e de vestir-se, precauçôes hygienicas em favor proprio ou dos outros, temperança etc...”. Considerando os perigos da imitação, era imprescindível estar atento à elaboração de cada detalhe dessa figura modelar que as crianças deveriam imitar, de modo que se evitasse que, presa dos pecados capitais da falta de asseio, decência ou temperança, o mau exemplo do professor viesse a macular a alma infantil com a sugestão desses graves vícios, fazendo desmoronar o castelo da educação moral. "Não há exagero quando se chama 'crime' ao acto que elle pratica, imprimindo no cerebro virgem da infancia essas imagens repugnantes que deixarão sulcos indeleveis e de perigosas consequencias" (idem, p. 50).

À sugestão operada pela escola e pelo exemplo do professor, viria aliar-se, nessa obra de modelagem, um conjunto de práticas que o aluno deveria vivenciar cotidianamente: a revista de asseio do corpo e das roupas; a revista da escola pelos alunos, num exercício que, aproximando-os das práticas desenvolvidas pelos inspetores sanitários, desenvolveria a capacidade de vigilância sobre o ambiente doméstico; a observação e correção por parte do professor das condutas contrárias às prescrições higiênicas; as mensurações de peso, estatura e força física; a indagação discreta e hábil sobre a vida doméstica do aluno, que orientaria o professor no trabalho de correção, ampliando a sua órbita de influência para o interior dos lares. Práticas essas cujo poder educativo não se reduzia ao âmbito da escola, na medida em que procuravam atingir as crianças e suas famílias, ensinandolhes um modo de vida civilizado e purificando-lhes das condenáveis práticas que, nas representações dos médicos-higienistas, caracterizavam o seu cotidiano.

Selecionando, classificando, ordenando e exibindo práticas exemplares forjadas a par da ação eficaz da escola sobre a infância, Dr. Almeida Junior compõe um modelo de intervenção pedagógica, con- 
figurado segundo uma gramática do controle, cujas prescrições deveriam ser obedecidas tanto pelas crianças como pelos seus mestres.

\section{$A$ revista dos alunos}

Primeiro dia de aula. O professor dá as boas vindas aos alumnos, e, por todos os modos possiveis, procura captar-lhes a sympathia e incutir-lhes amor pelo trabalho. Entre as cousas que pede está a observancia do asseio. Diz a sua importancia, e especifica o que entende por asseio: limpeza rigorosa das mãos, unhas, rosto, bocca, pescoço, orelhas, cabeça; arranjo dos cabellos; ordem e asseio da roupa, dos sapatos; lenço no bolso. Essa enumeração, tão minuciosa quanto possivel, é indispensavel. $\mathrm{O}$ alumno não comprehende a expressão generica de asseio. Si não se disser miudamente, o que elle é, o resultado será nullo ou insufficiente. Para capacitar-se de que foi entendido pela classe, o professor fará com que algumas creanças repitam a explicação. Em seguida, prometterá proceder, diariamente, no inicio da aula, a uma inspecção de cada alumno, para verificar si todos praticaram o que foi pedido.

No dia seguinte, fazendo desfilar a classe diante de si, o professor examinará os alumnos um por um: estão as unhas aparadas e limpas? as mãos limpas? o rosto? a cabeça e os cabellos? o alumno está calçado? etc... Ao mesmo tempo que examina, irá chamando a attenção para as falhas, ou louvando e encorajando os acertos. De vez em quando, terá que mandar um ou outro á torneira: fal-o-á sem alarde, nem repugnancia. (Idem, p. 51)

Considerada como o mais poderoso instrumento para incutir hábitos de asseio pessoal, a revista dos alunos deveria constituir-se numa prática diária, nos dois primeiros meses de aula, que poderia rarear a partir do terceiro mês, assumindo um intervalo de dois em dois dias e, finalmente, de uma ou duas vezes por semana, cuidando o professor para realizá-la sempre em dias indeterminados, o que ampliaria a sua eficácia, pela possibilidade de surpreender os renitentes.

Fazendo desfilar a classe diante de si, o professor deveria esquadrinhar o corpo de cada aluno, examinando-lhe mãos, unhas, cabelos, orelhas e, ainda, as roupas e os sapatos. Marcar a importância do asseio, explicar minuciosamente em que consiste, incentivar a repetição das noçóes, examinar acuradamente, chamando a atenção para as falhas e louvando os acertos são os elementos que compóem essa prática, por meio da qual se buscava conformar os corpos e gestos infantis, produzindo comportamentos considerados civilizados. 


\section{A inspeção do espaço escolar}

Tão importante quanto a revista dos alunos para a inculcação dos hábitos de asseio pessoal era a revista da escola para incutir as noções de higiene domiciliar, habituando as crianças a ver por si mesmas.

A classe, em conjuncto, ou dividida em turmas, fará uma especie de visita de inspector sanitario á escola. Começará pela sala de aulas, notando o asseio do assoalho, paredes, peitoris das janellas, o arranjo e limpeza dos moveis e material escolar; a ventilação e illuminação pelas janellas, os cuidados com a agua de beber etc., commentando e criticando tudo, com a maxima liberdade, e dando parecer sobre o modo de varrer, de transportar o lixo, de limpar os moveis, de arejar. Sempre que possivel, os actos serão associados ás palavras. Passar-se-á, depois, ás dependencias, inspeccionando-se o pateo e as installaçôes sanitarias, cujo asseio e ordem serão examinados e criticados. Esses exercicios serão feitos umas seis ou oito vezes no anno. Não há nenhuma desvantagem em repetil-os, até que os alumnos adquiram o habito de "vêr", por si mesmos. Assim, apprenderão elles a reclamar, embora durante as outras aulas, as faltas que, no tocante á hygiene, porventura notarem. (Idem, p. 52)

Erigidos à condição de pequenos inspetores sanitários, os alunos percorreriam todas as dependências da escola - das salas de aula a pátios e instalações sanitárias -, examinando-lhes o asseio e a ordem. Assoalhos, paredes, peitoris das janelas, ventilação, iluminação, limpeza, nada deveria escapar a esse treino do olhar, que tinha no transbordamento para o ambiente doméstico o seu principal objetivo. Repetido inúmeras vezes, o gesto, reforçado pelo poder da palavra, conformaria esse olhar penetrante, capaz de enxergar os mínimos deslizes, as mais discretas transgressóes.

\section{A vigilância sobre a conduta}

Distrahido, ou absorvido pelo trabalho, o alumno pratica innumeros pequenos actos contrarios á hygiene: senta-se em má posição; leva o lapis aos labios; põe o dedo na bocca, no nariz, nos olhos, no ouvido; entorna tinta, suja os livros ou cadernos; cospe no solo; espirra ou tosse sem proteger-se com o lenço; molha a ponta do dedo na saliva, para voltar a pagina do livro; no recreio, toma agua em copo usado, traz um lanche indigesto, come estando fatigado, mastiga mal, bebe estando suado etc. O professor, vigilante e treinado pessoalmente, pode, sem esforço de attenção, surprehender esses pequenos desvios, e corrigi-los imperdoavelmente. A tarefa, nos primeiros tempos, será pesada. Transposta, porem, a difficuldade inicial, suavemente se extinguirão os pequenos vicios. (Idem, p. 53) 
Surpreender os pequenos vícios, corrigi-los implacável e suavemente era, entretanto, apenas uma parte da tarefa que cabia ao professor vigilante. Era necessário ir além, inculcando os bons hábitos, redimindo as crianças e suas famílias, pela ação sobre o corpo, os gestos, as condutas, a alma: "Alem dos habitos maus, que convem extirpar, há os bons habitos, que na propria escola é possivel ir inculcando. Taes são, por exemplo, o de lavar as mãos antes do lanche, o de laval-as cada vez que o alumno vem da privada, o de limpar os sapatos, ao entrar para a escola" (idem, p. 53).

A aquisição dos bons hábitos configurava-se, desse modo, numa obra de disciplinamento, por intermédio da qual se buscava modelar os mínimos gestos da criança, tornando-os automáticos, quase naturais.

\section{A exibição dos indices de normalidade}

O desenvolvimento physico repercute no augmento normal do peso e da força. A balança e o dynamometro, que medem essas duas resultantes da saúde, podem trazer relevante serviço, na educação hygienica. Escolha-se um dia do mez, para cada classe de grupo escolar, ou para cada escola isolada. Nesse dia, sejam medidos o peso e a força de cada alumno. Os resultados, inscriptos em duas cores, no quadro negro, ahi ficarão, permanentes, para que as creanças possam avaliar o que estão ganhando, ou perdendo, mensalmente. O systema, já em parte adoptado, em escolas americanas, tem produzido magnificos resultados. (Idem, p. 53-54)

Materializados em medidas, expressas em cores diferentes, tornadas visíveis, comparáveis, o peso e a força assumiriam uma enorme importância na educação sanitária, na medida em que despertariam e manteriam o interesse da criança pela sua própria saúde. Possibilitando a avaliação pela própria criança do ganho ou da perda de peso mensal, o ritual da medição ${ }^{9}$ torná-la-ia vigilante em relação às suas práticas cotidianas de alimentação, repouso, exercícios físicos. Encenado na própria sala de aula, em ponto estratégico, para onde convergiam os olhares de todas as crianças, esse ritual teria o poder de "chamar a atenção para o valor do ganho de peso, estatura e força na saúde". ${ }^{10}$

\section{O inquérito sobre a vida doméstica}

$\mathrm{Na}$ escola, nem todos os aspectos da hygiene se attingem. Uma parte do asseio pessoal, uma grande parte da hygiene domiciliar, quasi toda a hygiene da alimentação si quizessemos circumscrever-nos ao ambiente escolar, teriam apenas desenvolvimento theorico. Não é difficil surprehender 
a propria vida domestica do alumno, os seus habitos, e desse modo, corrigir os erros ou completar as lacunas. A indagação discreta e habil da vida do alumno, em seu domicilio, é o meio para isso. (Idem, p. 54)

Que elementos essa narrativa da vida doméstica poderia revelar? Que possibilidades abriria à obra de inculcação dos bons hábitos e eliminação das condutas viciosas?

Saber-se-á o que elle faz em relação ao banho, aos dentes, ao repouso; saber-se-á o seu regimen e horario alimentar; onde dorme, onde brinca, a luz com que estuda, como toma agua; si fuma, si bebe etc. Indagado isso, para cada alumno, fará o professor a critica, mostrando os inconvenientes que achou, e os meios de sanal-os. Nas classes mais adeantadas, será mesmo possivel um estudo fundamentado da alimentação do alumno, com o calculo da respectiva ração, em calorias. O beneficio irá alem da escola: alcançará os demais membros da familia, que deverão boa parte de sua saude e de seus habitos sanitarios á influencia do professor. (Idem, p. 54)

Fazendo da narrativa da vida doméstica dos alunos matéria de crítica, o professor poderia ir indicando as formas corretas de viver a vida cotidiana, atingindo, por meio das suas prescrições, não apenas as crianças, mas as suas famílias.

Examinando os alunos, envolvendo-os em práticas de inspeção do espaço escolar, modelando-lhes a conduta pela eliminação das atitudes viciosas e fixação de hábitos salutares, interessando-os em relação aos resultados das medidas que expressavam a sua saúde e descortinando, de modo sutil e insidioso, o universo doméstico, os professores estariam prestando uma valiosa colaboração à obra de regeneração da população.

\section{O ensino dos porquês}

Se a inculcação dos hábitos se constituía em uma parte fundamental da educação sanitária, para garantir-lhe solidez era necessário, entretanto, ir além da imaginação, da obediência e dos sentimentos de amor-próprio, apelando para o poder do raciocínio. A proposta do Dr. Almeida Junior encontrava, dessa forma, no ensino sistemático dos porquês o seu coroamento:

Mas, para reforçar os habitos, dando, si possivel, a sua razão de ser, assim como para tornar a creança capaz de adaptar-se a circumstancias novas e imprevistas, importa fazer o ensino systematico de uma série de conhecimentos. Muitos delles já foram ministrados, quando se commentavam os 
habitos pessoaes, a alimentação, a escola ou o domicilio. Outros exigirão, pela sua importancia geral ou local, maior desenvolvimento. $\mathrm{O}$ fumo, o alcoolismo, a tuberculose, a febre typhoide, a variola, a raiva, para qualquer região do paiz; o amarellão, o impaludismo, a molestia de Chagas, para os lugares em que esses males existem, - devem entrar no programma de hygiene. $\mathrm{O}$ tabagismo e o alcoolismo requerem desenvolvimento maior em se tratando de meninos. Por outro lado, nas classes adeantadas de meninas ensinar-se-á puericultura, bem como alguns preceitos relativos ao preparo dos alimentos. (Idem, p. 55)

Reforçando os hábitos e municiando a criança para a adaptação a novas situações, as explicações deveriam ser reservadas para os últimos anos do ensino primário, devendo o professor estar atento às exigências de clareza, objetividade e à necessidade de repetição. Apesar de todas as críticas ao ensino verbalista, o professor não deveria abrir mão das vantagens da repetição: "A repetição, em hygiene, não é unicamente vantajosa: é indispensavel. Só ella gravará, indeleveis, conhecimentos que devem fixar-se na memoria como a taboada de multiplicar". Utilizando-se dos métodos e processos das ciências físicas e naturais, no ensino da etiologia, do modo de propagação, da profilaxia, o professor deveria tornar o ensino vivo, interessante e prático, por meio de "desenhos, quadros, caricaturas, objectos, vermes, insectos" (idem, p. 55); e, no caso da puericultura, pelo recurso a uma boneca e outros brinquedos infantis, que garantiriam que: "metade brincando, metade a sério, as futuras mães irão aos poucos apprendendo os cuidados mais importantes para com as creancinhas, asseio da pelle, da cabeça, da roupa; o modo de banhar, o modo de vestir; a hygiene da bocca, a hygiene do somno e, acima de tudo, o que concerne á alimentação natural e artificial" (idem, p. 56).

O valor dos impressos na difusão das noçôes de higiene não seria menosprezado pelo Dr. Almeida Junior, que destaca a necessidade de livros para o ensino de higiene. Coloridos, interessantes, ilustrados, trabalhando as questões numa linguagem simples, livros e cartilhas duplicariam a eficiência do ensino, acompanhando a criança a todas as horas, insinuando as regras de bem viver no meio familiar.

\section{Considerações finais}

Expor, exibir, demonstrar, tornando visíveis os poderes da ciência na transformação do modo de vida da população. Convocar, por essa via, à adesão a novos valores, ensinando uma nova moral e 
uma nova forma de viver a vida, pela participação ativa nos rituais da saúde, capazes de redimir das doenças, da pobreza, do atraso e da ignorância. Estes foram alguns dos aspectos centrais da cruzada pela saúde, educação e civilidade, que marcariam as práticas gestadas no âmbito do Instituto de Hygiene.

A divulgação de novos modos de viver e se comportar, fundados nos princípios da higiene - concebida como uma ciência enciclopédica e universal -, constituiu-se num importante objetivo das atividades desenvolvidas pelo Instituto, conforme se pode depreender da leitura da tese do Dr. Almeida Junior. Compreendendo a educação sanitária como um conjunto de "disciplinas", por meio do qual se procurava forjar um sistema de hábitos, os médicos-higienistas elegeriam a infância, concebida como matéria maleável e moldável, como alvo prioritário, sem se descuidar, entretanto, da obra de instrução dos adultos. Neste sentido, educação e saúde figuraram como elementos indissociáveis na configuração de um programa de moralização, que tinha, como um dos seus mais importantes pilares, a higienização da população.

\section{Notas}

1. Uma versão deste trabalho foi apresentada no IV Congresso Luso-Brasileiro de História da Educação, com apoio da FAPESP e do FAEP/UNICAMP.

2. Nesse período, Dr. Geraldo Horácio de Paula Souza (1889-1951), que havia cumprido um programa de Doutoramento em Higiene e Saúde Pública na Universidade Jonh Hopkins, como parte do acordo estabelecido entre o governo do Estado de São Paulo e a Junta Internacional de Saúde da Fundação Rockefeller, em 1918, ocupou, simultaneamente, os cargos de diretor do Instituto de Hygiene e diretor do Serviço Sanitário. Em 1925 realizou uma reforma dos serviços sanitários paulistas, que passou à história como Reforma Paula Souza.

3. Referindo-se à nova orientação que a reforma sanitária de 1925 imprimiu à política de saúde, Ribeiro assinala a centralidade que a educação sanitária do indivíduo passou a assumir: "O eixo dessa nova orientação deslocou-se do policiamento para a educação e as ações sanitárias transferiram-se da população em geral para o indivíduo em particular. Com isso, na prática sanitária, o policiar as coisas - habitação, água, esgoto, lixo -, o vigiar a cidade ganhava um novo aliado - a persuasão do indivíduo, o uso das palavras para forjar no indivíduo a consciência sanitária, a prática sanitária definiu-se como policiar e persuadir” (1993, p. 246).

4. Com Gustave Le Bon, Dr. Almeida Junior aprendera que "a educação é a arte de tornar inconsciente o consciente" (Almeida Junior, 1922, p. 24).

5. As posições de Maudsley justificariam a necessidade de iniciar a educação sanitária o mais cedo possível, pois segundo esse autor, o hábito exerce um importante papel na vida humana, na medida em que opera pela automatização dos gestos, implicando simplificação e repouso. Referindo-se à economia representada pelo hábito, afir- 
ma Maudsley: “(...) Os esforços conscientes da vida produzem logo extenuamento, emquanto que os actos automaticos secundarios se approximam, sob este ponto de vista, dos reflexos organicos, praticando-se sem fadiga. (...) Assim, uma boa educação deve ensinar-nos a exercer constantemente esta actividade, afim de que ella possa agir automaticamente, segundo as circumstancias em meio das quaes deve decorrer nossa vida” (apud Almeida Junior, 1922, p. 25).

6. As reflexôes sobre o papel do sistema nervoso na fixação de hábitos e a noção de plasticidade infantil encontrariam em William James a sua fonte. Para aquele estudioso: "O grande problema, em educação, é fazer do systema nervoso um alliado, e não um inimigo; é capitalizar nossas acquisiçôes e viver á vontade com os juros. Para isso, devemos tornar automaticas e habituaes, assim que o pudermos, tantas acçôes uteis quantas possiveis, e nos defendermos com grande cuidado de tudo que possa constituir um habito nocivo" (apud Almeida Junior, 1922, p. 25).

7. Recorrendo a Spencer, Dr. Almeida Junior procurará demonstrar a plasticidade do sistema nervoso na infância, valendo-se, na discussão do fenômeno, da analogia spenceriana entre o sistema nervoso e o curso de uma corrente de água sobre uma superfície lisa (Almeida Junior, 1922, p. 25-26).

8. Na análise desse modelo de educação sanitária formulado no âmbito do Instituto de Hygiene e sistematicamente apresentado pelo Dr. Almeida Junior, cabe chamar a atenção para os objetivos eugênicos de homogeneização da diversidade racial, tendo em vista a constituição de uma "raça brasileira", que perpassam as estratégias de intervenção sobre o cotidiano escolar. Não é demais lembrar que, fruto de análises que procuravam pôr em destaque os riscos advindos do que se considerava como degeneração racial e moral da população para o progresso do país, o projeto de intervenção social formulado pelos médicos-higienistas teve como um dos seus alvos o aperfeiçoamento racial. Sobre os disciplinamentos impostos pela instituição escolar com vistas a eugenizar a criança e suas relaçóes com o projeto de higienização social; cf. Marques, 1994, p. 101-119.

9. Na tese inaugural apresentada à Faculdade de Medicina em 1920, sob o título Inspecção medica escolar, Dr. Pedro Basile revisa a literatura em circulação, no período, indicando os vários fatores que poderiam influenciar, segundo as concepções vigentes, no desenvolvimento da estatura, figurando, em primeiro lugar, a nutrição. Os demais fatores seriam: o clima, a luz do sol, a eletricidade, as roupas (destacando-se as mantilhas ou faixas apertadas, os cinturões, espartilhos e as camisolas estreitas, que inibiriam o crescimento), o lugar de moradia, os exercícios físicos, os estímulos psíquicos, as moléstias e a influência étnica. O Relatório do Instituto de Hygiene de 1925 faz referência aos estudos desenvolvidos pelo Dr. Alberto Santiago, que resultaram no trabalho intitulado Ensaio de estatistica geral, no qual, a par dos dados coletados no Centro de Saúde Modelo, o autor estabeleceu uma comparação entre os pesos das crianças brasileiras e os das crianças francesas, suíças e alemãs. A queda da média de pesos das nossas crianças, após os 15 anos de idade, é atribuída pelo autor, entre outras causas, a meio ambiente, falta de exercícios físicos, moléstias tropicais, destacando-se as verminoses, alimentação, falta de educação e, como conseqüência desta, as doenças venéreas e a sífilis. Cf. Basile, 1920, p. 252-253; Relatório do Instituto de Hygiene, 1925, p. 19-21.

10. Não se pode ignorar os objetivos de classificação das crianças, discriminando-as em função de padrōes de normalidade, que presidiam tais práticas. Referindo-se a essas práticas de observação, medição, classificação, Carvalho trabalha com a metáfora da disciplina como ortopedia, arte de prevenção e correção da deformação. Cf. Carvalho, "Quando a história da educação é a história da disciplina e da higienização das pessoas”, em Freitas, 1997, p. 269-287. 


\section{Referências bibliográficas}

ALMEIDA JUNIOR, A. O saneamento pela educação. 1922. Tese (Doutorado) - Instituto de Hygiene, Faculdade de Medicina, Universidade de São Paulo, São Paulo.

BASILE, P. Inspeç̧ão medica escolar. 1920. Tese (Doutorado) - Faculdade de Medicina e Cirurgia de São Paulo, São Paulo.

CARVALHO, M.M.C. Molde nacional e fôrma civica: higiene, moral e trabalho no projeto da Associação Brasileira de Educação (1924-1931). Bragança Paulista: EDUSF, 1998.

CARVALHO, M.M.C. Quando a história da educação é a história da disciplina e da higienização das pessoas. In: FreITAS, M.C. (Org.). História social da infância no Brasil. São Paulo: Cortez; Bragança Paulista: EDUSF, 1997.

INSTITUTE OF HYGIENE (São Paulo). Historical record: 1916/1928; with supplement to 1934. Rockefeller Archive Center. 4 vols. (Arquivo Pró-Memória - Faculdade de Saúde Pública)

MARQUES, V.R.B. A medicalização da raça: médicos, educadores e discurso eugênico. Campinas: UNICAMP, 1994.

RIBEIRO, M.A.R. História sem fim... Inventário da saúde pública: 18801930. São Paulo: UNESP, 1993.

ROCHA, H.H.P. A higienização dos costumes: educação escolar e saúde no projeto do Instituto de Hygiene de São Paulo (1918-1925). 2001. 354p. Tese (Doutorado) - Faculdade de Educação, Universidade de São Paulo, São Paulo. 